\title{
El monasterio de San Martín Pinario: escuela para la escultura compostelana de los siglos XVII y XVIII
}

\author{
Marica LÓPEZ CALDERÓN \\ Universidad de Santiago de Compostela ${ }^{1}$
}

RESUMEN. En este artículo nos acercamos al mecenazgo que los monjes benedictinos de San Martín Pinario llevan a cabo en el campo de la escultura compostelana durante los siglos XVII y XVIII. A partir de los contratos conservados se evidencia la preocupación de los mismos no sólo en lo relativo al programa iconográfico de las empresas que acometen, sino también de aquellas cuestiones de oficio y lenguaje con que dichas empresas se han de materializar plásticamente. Este hecho se tradujo en el reclamo de artistas de primer nivel y con estos de piezas ejecutadas con maestría y siempre conforme a la estética imperante del momento, convirtiendo el monasterio de San Martín Pinario en la vanguardia y motor de la escultura compostelana.

Palabras clave: San Martín Pinario, escuela, escultura, Mateo de Prado, Miguel de Romay, José Gambino.

ABSTRACT. In this article we approach to the patronage carried out by benedictine monks of San Martin Pinario in the field of Santiago de Compostela's sculpture during the XVIIth and XVIIIth century. In this sense, it is very significant that preserved contracts show their worries related not only to the iconographic program of the ventures that they undertake, but also to those questions of trade and language needed to give plastic form to these ventures. This fact explains their search of very first level artists, who could bring along with them pieces executed with mastery and in conformity to the commanding aesthetics of the moment, which turned the monastery of San Martin Pinario into the avant-garde and driving force of Santiago's sculpture.

Key words: San Martin Pinario, school, sculpture, Mateo de Prado, Miguel de Romay, José Gambino.

El dos de agosto de 1639, los monjes compostelanos de San Martín Pinario firman contrato con el escultor Mateo de Prado para la ejecución de la sillería del coro bajo de su iglesia ${ }^{2}$; en el mismo, los bene-

\footnotetext{
${ }^{1}$ Este trabajo fue realizado en el marco del Proyecto de Investigación HUM 2007-61938, financiado por la Dirección General de Investigación (MEC).

${ }^{2}$ P. PÉREZ Costanti, Diccionario de artistas que florecieron en Santiago durante los siglos XVI y XVII, Santiago de Compostela, 1930, p. 452.
}

dictinos establecen el programa iconográfico que el imaginero, en compañía de sus oficiales, debía concretar plásticamente: "en cada uno de los espaldares de las sillas, una historia de la vida de Nra. Señora y en cada uno de los del primer cuerpo de sillas altas un santo de tamaño que se pidiere y en la forma en que pareciese al Abad y convento; y en los tableros y espaldares del segundo cuerpo, historias de la vida y milagros de 
San Benito" ${ }^{\prime 3}$. Casi un año más tarde, concretamente el dieciséis de junio de 1640, el escultor suscribe un nuevo convenio con los monjes de Pinario, ahora para la ejecución de "noventa y seis entredoses, setenta y seis misericordias y cinquenta y seis carthelas", donde, además, le demandan "buena destressa y arte" y "figuras de talla todas ellas muy a lo vivo" ${ }^{\prime 4}$.

A través de estas escuetas notas ya es posible comprender por qué el monasterio de San Martín Pinario se convierte durante la Edad Moderna, y particularmente desde el siglo XVII, en el principal motor de la imaginería compostelana. $Y$ es que, como se desprende de los referidos documentos, su mecenazgo, más allá de circunscribirse a cuestiones puramente iconográficas, se atuvo también a aquellas otras de oficio y de lenguaje: de oficio al demandar buena destressa y arte en la obra; de lenguaje al reclamar figuras de talla todas ellas muy a lo vivo.

El primer requerimiento nos presenta a unos monjes preocupados por la maestría en la ejecución de sus encargos, lo que, evidentemente, se tradujo en la contratación de artistas, y no de artesanos, como se observa en el caso específico de Mateo de Prado. Este, a quien los benedictinos reclaman desde Valladolid donde se encontraba trabajando ${ }^{5}$, enriqueció el monasterio, pero también, como decimos, la propia escultura compostelana desde el punto y hora que con su calidad, al tiempo que con su invención, constituyó un revulsivo para el panorama compostelano del momento, carente entonces de figuras propias de primer nivel

\footnotetext{
${ }^{3}$ P. PÉrez COSTANTI, op.cit., p. 452.

${ }^{4}$ P. PÉREZ COSTANTI, op.cit., p. 452. V. también A. GoY Diz, A actividade artística en Santiago: 1600-1648, Santiago de Compostela, 2007, p. 588.

${ }^{5} \mathrm{M}$. Chamoso LAMAS, «El escultor Mateo de Prado», Cuadernos de Estudios Gallegos, XXV, 1956, pp. 429430.
}

y anquilosado en fórmulas pasadas ${ }^{6}, \mathrm{y}$, por consiguiente, se convirtió en referente indiscutible a seguir, perfilando, de hecho, las señas de identidad del lenguaje compostelano hasta unas fechas muy avanzadas. En ello jugaría un papel importante que el escultor, una vez establecido en Santiago con motivo del coro, empresa que no finaliza hasta 1647 , se asentase definitivamente en la ciudad, donde muere en agosto de 1677, difundiendo su estilo a partir de nuevas empresas ${ }^{7} \mathrm{y}$, sobre todo, de la instauración de un taller propio.

En relación con lo expuesto se encuentra la segunda condición que estipulan los benedictinos. Esta nos habla de unos monjes a la vanguardia de su tiempo y, por extensión, de una escultura compostelana que sabrá estar acorde con el espíritu de época de cada momento. Concretamente, detrás del reclamo de figuras de talla muy a lo vivo subyace, en realidad, la introducción en la plástica compostelana de la estética barroca. No en vano, el concepto vivo encierra su seña de identidad por excelencia: el naturalismo ${ }^{8}$, y con ella su principio rector:

\footnotetext{
${ }^{6}$ De hecho, para la principal empresa de empeño anterior al coro de Pinario: la sillería de la catedral compostelana, cuyo grueso de ejecución se acometió entre 1599 y 1606, el cabildo también hubo de recurrir a artistas foráneos: Juan Dávila y Gregorio Español. Y, aún así, la referencia a Juan de Juni, evidente sobre todo en los tableros puestos en relación con Dávila, resulta ya, en palabras de Martín González, "un poco tardía para la época en que se hace la sillería". J. J. MARTín GONZÁLEZ, La catedral de Santiago de Compostela, Barcelona, 1977, p. 300.

${ }^{7}$ Para un catálogo reciente de las mismas v. L. FERNÁNDEZ GASALLA, «Mateo de Prado», Séculos XVI e XVII, Vigo, 2004, pp. 298-337.

${ }^{8}$ Así, Vicente Carducho en sus Diálogos de la Pintura (Madrid, 1633) describe la nueva corriente como "tan viva, $\tan$ actual, que admira y espanta a todos". De igual forma, Francisco Pacheco en El arte de la Pintura (Sevilla, 1649), siguiendo la obra Discorso intorno alle imagini sacre et profane (Bolonia, 1582) del moralista y cardenal de Bolonia Gabriele Paleotti, dice que el fin de la pintura "será, mediante la imitación, representar la cosa que pretende con la valentía y
} 
la eficacia ideológica que pasa a regir las diversas manifestaciones culturales a raíz del Concilio de Trento ${ }^{9}$. Y es que el naturalismo no constituye un fin en sí mismo, sino que es un medio para hablarle fuerte y directamente al alma del fiel puesto que, en palabras de Gabriele Paleotti, “iquién duda no haber instrumento más fuerte o más eficaz que las imágenes vivamente pintadas, que casi violentan los sentidos incautos?"10; el naturalismo que demandan los benedictinos es, pues, el instrumento de la reformada Iglesia Católica para encaminar al fiel a su salvación, lo que, además, podía verse acompañado y reforzado por la referida maestría ${ }^{11}$ como, de hecho, sucede en el propio coro de Mateo de Prado.

propiedad posible, que de algunos es llamada la alma de la pintura, porque la hace que paresca viva" e, igualmente, dentro del mismo capítulo $\mathrm{XI}$, se refiere a "imágenes hechas vivamente". V. CARDUCHO, Diálogos de la Pintura. Su defensa, origen, esencia, definicion, modos $y$ diferencias, A. FORNI (ed.), Bolonia, 1990, fol. 48 r.o y ‥; F. PACHECO, El arte de la Pintura, B. BASSEGODA I HUGAS (ed.), Madrid, 2001, pp. 248, 256 y 257.

${ }^{9}$ Este, en su sesión vigésimo quinta, expuso la necesidad de que el arte respondiera a un fin devocional [v. Canones, et Decreta Sacrosancti Oecumenici, et Generalis Concilii Tridentini, Roma, 1564, p. CCIII], a partir de lo cual los principales teólogos y teóricos de la Contrarreforma situarán la persuasión como principio fundamental del arte. A. BLUNT, La teoría de las artes en Italia, Madrid, 1979, pp. 115-141.

${ }^{10}$ G. PALEOTTI, op.cit., fol. 78 r.o

${ }^{11}$ Aunque pensamiento típicamente contrarreformista es el de supeditar la calidad de la obra a su intencionalidad ética, como ejemplifica el siguiente párrafo de Vicente Carducho: "no importa que la imagen en quien se haze oración, ó el sacrificio, esté hecha con arte, ó sin ella; porque no obra ni la forma ni la maestria (sino lo que representa, y no mas) y asi no importa para esto que sea hecha con perfeccion, ó sin ella", lo cierto es que la conciliación de ambas posturas -lo utile y lo dilettevole- gozará de gran predicamento durante el Barroco, de manera que el mismo Carducho concluye: "Basta que de lo dicho se infiere con quanta diferencia mueve los afectos de la devoción y disposición la pintura, con mayor perfeccion conduci$\mathrm{da}$, que no la inculta y toscamente fuere pintada". V. CARDUCHO, op.cit., fol. 124 v. ․ㅡ y 126 r. o $^{\circ}$
Este, formado en el taller de Gregorio Fernández, introduce, pues, en Compostela y gracias, por lo tanto, al mecenazgo de los monjes de Pinario, el arte vivo de su maestro, valiéndose para ello de aquellas señas de identidad que nos permiten reconocer su caligrafía personal. Como se observa en los tableros de la sillería, especialmente en los de la alta (Fig. 1), el escultor construye los rostros a partir de un paralelepípedo que desbasta en dos planos netamente diferenciados -el frontal y sus respectivos laterales-, lo que acompaña de un modelado en grandes planos en el que destaca los principales detalles orográficos a partir de una clara predominancia del dibujo que lo lleva a perfilar las arrugas de la frente y el entorno de ojos, nariz y boca. Asimismo, resuelve las fisonomías a través de un repertorio común basado en el empleo de un entrecejo amplio y trapezoidal, ojos almendrados, nariz con una protuberancia en la parte superior del tabique y remate plano y boca grande, de labios carnosos.

Como decimos, este estilo vivo de Mateo de Prado marcó un punto de inflexión en la plástica compostelana. Ahora bien, ni sus discípulos directos, como su yerno Jerónimo de Castro y Losada ${ }^{12}$, ni tampoco artistas de su círculo, como Miguel de Romay ${ }^{13}$, mantuvieron su maestría. Al contrario, aún cuando sus obras revelan el mismo espíritu de época, se estandarizan en rostros anodinos, fruto de repetir fórmulas, en vez de interpretarlas estudiándolas en el natural, $y$, en general, de prestar me-

\footnotetext{
${ }^{12}$ Sobre el mismo v. L. FERNÁNDEZ GASALLA, «Jerónimo de Castro e Pedro de Taboada», Séculos XVI e XVII, Vigo, 2004, pp. 338-367.

${ }^{13}$ La vinculación de Miguel de Romay (1670-i?) con Mateo de Prado, además de resultar clara en el análisis de su estilo, ha sido probada documentalmente por Leopoldo Fernández Gasalla en "En torno a los orígenes de Miguel de Romay y a la escultura compostelana en el tránsito de los siglos XVII al XVIII (16701705)", Cuadernos de Estudios Gallegos, XLIII, 1996, pp. 221-240.
} 
nos atención a su acabado, reduciendo notablemente el número de detalles orográficos y con estos la riqueza de modelado; en definitiva, lo utile prescinde ahora de lo dilettevole.

Es durante la década de 1730 y principios de la siguiente cuando la escultura compostelana vuelve a aunar ambos conceptos y es, precisamente, el monasterio de San Martín Pinario en donde dicho cambio, si no se fragua, al menos constituye el mayor exponente del mismo a partir, primero, del conjunto escultórico de su retablo mayor ${ }^{14} \mathrm{y}$, a continuación, del de sus dos colaterales: el de san Benito y el de Nuestra Señora del Rosario (1742-1743) ${ }^{15}$. Las quince figuras de bulto redondo y los cuatro relieves que en total cobijan ambas máquinas constituyen, sin lugar a dudas, el gran epílogo del barroco compostelano: los rostros, además de los paños sobre los que luego volveremos, se resuelven a partir de un lenguaje naturalista ejecutado, como dijimos, con maestría. Todo ello no hace sino más que responder, de nuevo, a las demandas de los monjes benedictinos, quienes, de hecho, en el contrato estipulan que las esculturas sean "del mejor primor e imitación del natural, sin defecto de ninguna clase" ${ }^{\prime 16}$. Eso sí, dentro de la referida maestría e imitación del natural es posible distinguir, de acuerdo al análisis de Folgar de la Calle y López Vázquez, la participación de cuatro escultores distintos: todos formados en el taller de Miguel de Romay, del que son operarios, y que en esta obra de los colate-

-

${ }^{14}$ Iniciado el 19 de junio de 1730 y concluido el 19 de marzo de 1733. R. OTERO TÚÑEZ, «El retablo mayor de San Martín Pinario», Cuadernos de Estudios Gallegos, 11, 1956, pp. 229-243.

${ }^{15}$ Sobre la secuencia de ejecución de ambos retablos v. Ma C. Folgar De La CALle; J. M. López VÁzQUEZ, «Los retablos», Santiago. San Martín Pinario, Santiago de Compostela, 1999, p. 262.

16 J. COUSELO BOUZAS, Galicia artística en el siglo XVIII y primer tercio del XIX, Santiago de Compostela, 1933, p. 247. rales adquieren su independencia. De entre ellos destacan, tanto por el número de obras realizadas, como por su calidad y por la maniera de interpretar el referido naturalismo, los identificados como la primera y segunda mano ${ }^{17}$. Así, la primera mano ofrece unas fisonomías rudas, resultado de una fuerte estructura ósea y un modelado rico y volumétrico que se traduce en una concepción plástica del rostro, como se observa en las imágenes de san José (Fig. 2), san Mauro, san Agustín o santo Domingo, mientras que la segunda se decanta por una mayor estilización de la realidad, como ejemplifican las piezas de san Juan Bautista (Fig. 3), san Plácido, san Anselmo, santo Tomás de Aquino o san Joaquín (Fig. 4).

Pero, es más, teniendo en cuenta que el estilo de estas últimas piezas, al lado de sus señas de identidad relativas a la forma de desbastar el rostro ${ }^{18}$, el repertorio con que se construye ${ }^{19}$ y el modelado con que se

\footnotetext{
${ }^{17}$ Ma C. FOlgar De La CAlle; J. M. López VÁZQUEZ, op.cit., pp. 266-268.

${ }^{18}$ En dos planos: el frontal y sus respectivos laterales, resolviéndose la separación entre ambos mediante la línea que, formada por la intersección entre los dos planos, une el arco ciliar con la barba, como se observa en las imágenes de san Juan Bautista y san Joaquín, o, en caso de no existir esta, con el final de la quijada, tal es el caso de las tallas de san Plácido, santo Tomás y san Anselmo, para lo cual atraviesa el pómulo, destacándolo en el espacio intermedio.

${ }^{19}$ Primero, unas cejas en las que los laterales diagonales del entrecejo se potencian considerablemente hacia arriba, a partir de los cuales comienza un acusado descenso que culmina en su unión con la barba o quijada; segundo, el referido entrecejo es estrecho $\mathrm{y}$, además, rehúnde ligeramente el puente nasal; tercero, la nariz es asimismo estrecha, recta o arqueada, y siempre rematada en la punta de manera casi plana; cuarto, la zona orbicular del ojo próxima al lacrimal está muy excavada, resultando amplia y profunda, al tiempo que los ojos son pequeños, de forma almendrada, con el párpado destacado mínimamente y con el derecho siempre tallado más próximo al tabique nasal; $y$, por último, en aquellas imágenes que carecen de barba, como Plácido, Tomás y Anselmo, se juega con un mentón grande y potente que se realza todavía más al tallar el entorno de la boca en profundidad.
} 
resuelve ${ }^{20}$, resulta en todo similar al de las imágenes de san Cosme (Fig. 5) y san Damián del retablo mayor de la capilla compostelana de San Roque, obras indiscutibles de Andrés Ignacio Mariño ${ }^{21}$, creemos que la hasta ahora identificada como segunda mano de Pinario es, en realidad, este escultor: Andrés Ignacio Mariño, "maestro de fama"22, y, por consiguiente, a los ojos de los monjes benitos capacitado para acometer las esculturas del monasterio con el mejor primor conforme hemos visto que demandaban en el mencionado contrato. Atribución que también parece confirmar, aunque indirectamente, las noticias documentales pues, a través de estas, sabemos que Mariño pertenecía a la nómina de oficiales que desde 1730 se habían establecido en el claustro del monasterio para acometer las obras del retablo mayor bajo la dirección de Miguel de Romay $^{23}$, dirección que el propio Mariño asume a partir de 1738 cuando se realiza la custodia pequeña, para aparecer luego como fiador, junto con Domingo de Romay y Bernardo García, en el contrato de los propios retablos colatera$\mathrm{les}^{24}$, en los que, además, tenemos constancia de que igualmente participó a través de una declaración hecha por él mismo ${ }^{25}$.

La imaginería de dichos colaterales supone, pues, el inicio del colofón de la

\footnotetext{
${ }^{20}$ De factura lumínica, que resulta de trabajar las fisonomías en grandes planos, y sintética, es decir, presenta un número reducido de detalles orográficos en los que, además, prima un claro efecto de dibujo.

${ }^{21}$ Se conserva el recibo de 20 de agosto de 1754 en el que se hace constar el pago al escultor de " 400 reales [...] por la hechura de los Santos San Cosme y San Damián, que se hallan en el retablo". R. OTERO TúÑEZ, "Del manierismo al barroco: imaginería e iconografía en la capilla compostelana de San Roque", Archivo Hispalense, 249 (1999), pp. 187-188.

22 J. COUSELO BOUZAS, op.cit., p. 442.

23 J. COUSELO BOUZAS, op.cit., p. 701.

${ }^{24}$ J. COUSELO BOUZAS, op.cit., p. 246

${ }^{25}$ Ma C. FOLGAR DE LA CALle; J. M. LÓPEZ VÁZQUEZ, op.cit., p. 262.
}

estética barroca en Compostela, pero nuevamente los monjes de San Martín vuelven a marcar la pauta cuando, concretamente el 25 de febrero de 1764, pagan "ochocientos onze reales" al escultor José Gambino por "la ymagen de Santa Cathelina para colocar en el altar nuevo de su advocación" ${ }^{26}$ (Fig. 6) y, justo un año después, "dos mil ochocientos y dos reales para los dos Santos que están sobre las puertas del coro y los dos Milagros de San Martín; de las tarjetas al lado de la yglesia" ${ }^{27}$. Los dos Santos que están sobre las puertas del coro se corresponden con las esculturas de san Andrés (Fig. 7) y san Juan Evangelista (Fig. 8), las cuales, en compañía de la filósofa de los católicos, constituyen, sin lugar a dudas, tres obras maestras del escultor, incluso puede decirse que de toda la plástica galaica, y soberbia síntesis de las claves de su estilo durante su segunda etapa (1756-1764), en la que Gambino da muestras de su arrolladora originalidad fruto de haber personalizado las aportaciones del barroco compostelano en que se había formado a través de sus propios hallazgos que, teñidos de ecos tanto clasicistas como rococós, responden ya a un nuevo espíritu de época. Consecuentemente, San Martín Pinario, más de cien años después del reclamo de Mateo de Prado, sigue revelándose como un mecenas que exige maestría y vanguardia en las empresas que acomete, valiéndose para ello de artistas de primer nivel: no en vano José Gambino es tenido por sus contemporáneos como uno "de los mejores [escultores] de

\footnotetext{
${ }^{26}$ A. B. FReIRE NAVAL, Aportación documental al estudio de la actividad artística del Monasterio de San Martín Pinario y sus prioratos entre 1501 y 1854, Tesis de Licenciatura inédita, dirigida por el Prof. Dr. D. José M. García Iglesias, Universidad de Santiago de Compostela, 1998 , p. 59.

${ }^{27}$ Ma C. FOlgar De La CALle; J. M. LÓPez VÁZQUEZ, op.cit., p. 262.
} 
este reino de Galicia" ${ }^{28}$.

Las imágenes de san Andrés y san Juan son, efectivamente, consecuencia directa de las búsquedas naturalistas que Gambino emprende durante sus primeros años de actividad en pos de unas fisonomías ricas en cuanto al número de detalles orográficos y de matices en su modelado, lo que ahora, además, adereza con un impecable dominio técnico que ya comenzaba a despuntar tras el conjunto escultórico de la capilla del Pazo de Oca (1750-1751, A Estrada, Pontevedra). Búsquedas naturalistas que denuncian la formación del maestro dentro del taller de Miguel de Romay; de hecho, su técnica revela la deuda que contrae con los escultores identificados como la primera y segunda mano de Pinario, pudiendo decirse que sus fisonomías resultan una síntesis de ambas. No obstante, a partir de esta base de naturalismo germinal, el escultor resuelve los semblantes de los apóstoles a través de una clara pátina de idealismo que se traduce en esa "cierta agradable dulzura" que ya apuntaba Manuel Murguía ${ }^{29}$ y que responde a esa nueva sensibilidad de época en que vive Gambino.

De igual forma, el maestro nos propone una santa Catalina de dulce naturalismo idealizado, como, además, corresponde a una Santa de extremada hermosura, según la describen sus exégetas como el Padre Pedro de Ribadeneira ${ }^{30}$. Para plasmar su belleza, Gambino elige las formas canónicas establecidas ya desde el Renacimien-

-

${ }^{28}$ Así lo refiere el abad de Sobrado en una de las cartas que envía a la Real Academia de San Fernando con fecha de 30 de enero de 1770. R. OTERO TúÑEZ, "Textos y documentos. El retablo de Sobrado y el Neoclasicismo", Cuadernos de Estudios Gallegos, XXXIV, 1960 , p. 339.

${ }^{29}$ M. MuRGuíA, El arte en Santiago durante el siglo XVIII y noticia de los artistas que florecieron en dicha ciudad y centuria, Santiago de Compostela, 1884, p. 82.

${ }^{30}$ Flos Sanctorum. Nuevo Año Cristiano. Vida de los Santos (Madrid, 1599), T. XI, Cádiz, 1863, p. 232. to, en palabras de Leonardo: "No se hagan los músculos con líneas duras, sino deja que las luces dulces se desvanezcan imperceptiblemente en sombras agradables y deliciosas; esto produce gracia y belleza" ${ }^{31}$. Siguiendo estas directrices, el escultor construye el rostro de la Santa a partir del diseño de curvas y concavidades entrelazadas que ya se constata en la imagen de la Virgen del Rosario del coro alto del convento compostelano de Santa María de Belvís (ca. 1761), aunque en este caso se ajusta todavía más a los presupuestos normativos $\mathrm{y}$, en consecuencia, no se deja llevar tanto por la consecución de la gracia llena de dulzura como en la citada representación de María; de hecho, la imagen de Pinario presenta una asimetría entre las dos partes del rostro mucho menor de lo que es habitual encontrar en la obra del escultor $y$, por el contrario, una plasticidad mucho mayor, de manera que, al prescindir de músculos y líneas duras, las luces se desvanecen en sombras agradables y deliciosas. Incluso, este efecto viene potenciado en función del contrapunto que supone el cabello, tan cuidadosamente peinado como artificiosamente tratado, de forma que su talla lumínica se inserta en una caligrafía de líneas sinuosas configuradas por los mechones, lo que dota de belleza a la figura, tanto por la que aporta el propio peinado, como por el juego de curvas combinadas y contrastes matéricos generados entre estos y las carnaciones.

Frente a este tratamiento, Gambino construye el rostro de Maximino, que se encuentra dispuesto bajo los pies de la Santa, evocando el tema de encuadre del vencido $^{32}$ : este simboliza el paganismo al que Catalina venció a través de la dialéctica, a partir del procedimiento inverso al de ella,

\footnotetext{
${ }^{31}$ L. DA VINCI, Tratado de la pintura, M. PITTALUGA (ed.), Madrid, 2005, p. 118.

${ }^{32}$ J. BIALOSTOCKI, Estilo e Iconografía. Contribución a una ciencia de las artes, Barcelona, 1973, p. 114.
} 
es decir, resaltando los músculos y provocando líneas duras que generan un fuerte contraste lumínico al objeto de evidenciar claramente su fealdad, entendida esta como categoría intrínseca a la malicia ${ }^{33}$. Gambino logra este efecto parodiando su propio estilo, en concreto, exagerando la estructura y modelado que le sirven para convertir al propio san Juan Evangelista de Pinario en un asceta repleto de furor poeticus. La caricatura de su estilo es, de hecho, el procedimiento del que el escultor siempre se vale cuando ha de figurar la maldad, de manera que la misma varía acomodándose al estilo particular de la etapa de actividad en que se encuentra, lo que se constata fácilmente al cotejar la fisonomía de este Maximino de Pinario con la que Gambino, al comienzo de su producción, talla en el relieve de santa Catalina de Oca (1750-1751): esta, frente a lo que acabamos de apuntar, presenta muy potenciado el pómulo y exagerado el arco esférico que lo une con la mejilla, rasgos característicos del estilo del escultor en torno a los años 50. Por otra parte, y prosiguiendo con la dialéctica entre las figuras, Gambino opone la desproporción y deformación del cuerpo de Maximino ${ }^{34}$ a la esbeltez y perfección del canon de ocho cabe-

\footnotetext{
${ }^{33}$ La utilización de los conceptos hermoso y feo como cualidades que van más allá de la apariencia física de la persona para encarnar valores morales es una idea que aparece constantemente repetida en los escritores áureos -v. B. GRACIÁN, El Criticón (1651), A. SANTOS (ed.), Madrid, 1984, pp. 189-190- e, incluso, Vicente Carducho la sitúa en su tratado entre las cosas que debe saber un pintor para no errar -op.cit., fol., 49

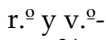

${ }^{34}$ Resulta interesante constatar el tratamiento naturalista que el escultor confiere a la figura del emperador, no limitándose a utilizar sólo su cabeza como atributo, de forma que, como el san Miguel realizado por Pedro de Romay para la capilla compostelana de San Roque (ca. 1763), la Santa aparece materialmente de pie sobre el cuerpo de Maximino, como aquel lo está sobre el de Satanás, lo que, combinado con el referido tema de encuadre del vencido, otorga a la imagen de Pinario un explícito carácter de vencedora de la Herejía.
}

zas de la figura de Catalina y el retorcimiento imposible de aquel a la elegancia de la serpentina de esta, la cual tiene, además, un ritmo pausado, según corresponde a su origen real y a su "peregrina honestidad y rara modestia" ${ }^{\prime 35}$.

Catalina es, asimismo, la esposa mística de Jesucristo, de ahí que el escultor nos la presente como una novia serenamente arrobada en sus afectos. En este sentido cabe señalar que la plasmación de las pasiones, que siendo movimientos del ánima se trasparentan en el rostro, constituye una de las principales preocupaciones de Gambino, al objeto de satisfacer una demanda de época que recupera búsquedas ya desarrolladas por el alto barroco, lo que lo lleva a entroncar con la mejor producción de Mateo de Prado. Y es que tras el concepto vivo, aquel que los benedictinos le demandan para su coro, se esconde no sólo el mostrar, con la mayor exactitud descriptiva posible, la fisonomía externa del Santo representado, sino también su realidad interna espiritual: se trata del realismo de almas del que habla Dámaso Alonso, seña de identidad del lenguaje barroco ${ }^{36}$, fundamentalmente del lenguaje barroco espanool $^{37}$, y del que Prado, merced a su formación en el arte expresivo de Gregorio Fernández, supo dar perfecta cuenta, primero, satisfaciendo las pretensiones de los monjes de Pinario, y, luego, en obras como el san

\footnotetext{
${ }^{35}$ P. DE RIBADENEIRA, op.cit., p. 223.

${ }^{36}$ De hecho, esta se convierte en una de las cualidades más valiosas en la valoración de la obra, a la vez que requisito imprescindible de la misma, según se desprende de la teoría del decorum expuesta por los intérpretes del Concilio de Trento: "el pintor excelente fácilmente sabrá expresar los gestos convenientes y propios a cada pasión", dice Gilio da Fabriano (Due Dialogi (Camerino, 1564), P. BAROCCHI (ed.), Florencia, 1986, fol. 81 v. o), siendo su fin, en palabras de Pacheco, que el arte "con la verdad posible represente con claridad lo que pretende" (op.cit., p. 300).

${ }^{37}$ W. WEISBACH, El barroco arte de la Contrarreforma, E. LAFUENTE FERRARI (ed.), Madrid, 1942, p. 276.
} 
Roque de la capilla compostelana de su advocación (ca. 1639), el san Pedro de la capilla catedralicia del Cristo de Burgos (ca. 1660) o el san Andrés de la iglesia de Santa María la Real de Conxo (ca. 1664-1665, Santiago de Compostela) (Fig. 9).

Estas piezas constituyen, aparte de la propia sillería, tres de los ejemplos más significativos que de Mateo de Prado han llegado hasta nosotros y que José Gambino pudo haber visto en Santiago adoptándolos como referentes en la conformación de su estilo. Y es que la producción de este revela no ya un estudio indirecto de la obra de Prado a través de la estatuaria dieciochesca compostelana, sino directo y de perfecta asimilación de la fuerza expresiva de sus rostros, característica esta que, desde los años finales del siglo XVII y a lo largo de la primera mitad del siglo XVIII, había derivado en la escultura compostelana en soluciones puramente formularias $\mathrm{y}$, consecuentemente, carentes de impronta de vida como, de hecho, se observa, a pesar de su incuestionable maestría, en el conjunto escultórico de los retablos colaterales de San Martín Pinario.

Gambino, por consiguiente, como había hecho la estética alto barroca, devuelve a la plástica compostelana, en general, $\mathrm{y}$ al monasterio de Pinario, en particular, la transmisión de unos afectos vivos. Dota de plena vida interior a santa Catalina, pero también a san Andrés, a quien igualmente figura extático, pasión que responde al decoro del tema del martirio que insinúa la cruz en aspa que sobresale a sus espaldas puesto que estaría simbolizando el gozo del Santo ante la visión de la gloria que percibe como recompensa a su entrega, significada esta mediante el gesto de llevarse la mano abierta al pecho; de hecho, la relación entre el martirio y la bienaventuranza celestial resulta muy frecuente en las manifestaciones pictóricas del barroco, en las que esta generalmente se personifica a partir del juego con la luz, el mismo que, precisamente, se produce en la imagen de Pinario a través del vano que se abre tras de ella en la parte superior de la cabecera de la Iglesia.

Pero lo más importante a resaltar es el cambio de pathos que muestra la imagen de Gambino respecto a la estética propiamente barroca: él prescinde de la habitual expresión de dolor que, concerniente a la iconografía del martirio, buscaba conmover al fiel, hecho perfectamente ejemplificado en el propio monasterio benedictino a partir del tablero que Mateo de Prado dedica a san Pelayo (Fig. 10) o de la escultura que Andrés Ignacio Mariño talla de san Plácido para el retablo colateral de san Benito. Es más, ambas obras participan de la tendencia al realismo descriptivo moroso e, incluso, morboso, propia del lenguaje barroco ${ }^{38}$, figurando, como por ejemplo pedía Paleotti, "los atroces suplicios de los santos, minuciosamente expresados ${ }^{\prime 39}$ : los escultores se recrean en mostrar cortados los cuellos de sendos mártires de los que, además, mana, como nota enfática, gran cantidad de sangre. De esta forma, y ahora a través de la estética del feísmo, Prado y Mariño responden a la demanda de figuras de talla muy a lo vivo que, en distintos momentos, pero dentro de un mismo espíritu de época, les formulan los monjes de San Martín Pinario; Gambino, en cambio, se decanta por una imagen devocional más afable y grácil conforme al nuevo gusto de época.

Por su parte, la fisonomía de san Juan Evangelista parece querer transmitir el furor poeticus del Santo mediante el cual este estaría recibiendo la inspiración divina que le guiase en sus escritos, de ahí también su gesto corporal de volver la cabeza hacia arriba y mantener todavía en alto la mano derecha que tan delicadamente sostiene la

\footnotetext{
${ }^{38}$ E. OrozCo DíAz, Manierismo y Barroco, Salamanca, 1970, pp. 109-122.

${ }^{39}$ Op.cit., fol. 216 r. ${ }^{\circ}$ y v. ${ }^{\circ}$
} 
pluma, como si estuviese a la espera de poder posarse sobre el libro que sujeta la izquierda para dar comienzo a la narración. Como algunas de las obras de la primera etapa de Gambino, es posible que esta imagen del discípulo amado se inspire en el arte italiano e, incluso, que su fuente haya sido la escultura que, de este mismo apóstol, realizó Baptista Vacca para la Basílica de Mafra en 1733, de igual forma que la imagen de san Andrés guarda gran parecido con la que Girolamo Ticciati acometió para la también magna empresa de don Joao $\mathrm{V}$ en $1732^{40}$.

No obstante, y también como en las obras precedentes, esta relación se circunscribe fundamentalmente a una sugestión iconográfica en tanto en cuanto Gambino resuelve las piezas a partir de las señas de identidad de su estilo, de manera que si el san Juan Evangelista de Baptista Vacca se caracteriza, como explica Fernandes Pereira, por "um rosto imberbe, dada a sua grande juventude, quase feminino, como é habitual, pois, $[\ldots]$ a pesar de ter vivido cerca de cem anos raramente é retratado como anciao, ou como homem marcadao por uma vida dura que na realidade te$\mathrm{ve}^{\prime \prime 4}$, el de Gambino se define por su madurez y carácter ascético que, aunque bien pudiera responder a esa realidad de homem marcado por uma vida dura, en verdad remite a una de sus señas de identidad: desde el

\footnotetext{
${ }^{40} \mathrm{Al}$ respecto, cabe señalar que, aunque, a partir del estudio de la técnica y señas de identidad de Gambino, consideramos que este se forma en Galicia, no descartamos un posible viaje del escultor a la Basílica de Nossa Senhora e Santo Antònio del Palacio Nacional de Mafra cuyo conjunto escultórico podría haber desempeñado en él el mismo papel pedagógico que en hombres como Machado de Castro. Concretamente, este podría ser el origen, o al menos uno de ellos, del vocabulario italiano que paulatinamente incorpora a su actividad y de algunos de los tipos iconográficos que, inexistentes en la plástica galaica anterior, introduce en la misma.

${ }^{41}$ J. FERNANDES PEREIRA, A escultura de Mafra, Lisboa, 2003, p. 122.
}

comienzo mismo de su actividad, Gambino resuelve las tipologías extáticas de Santos, independientemente de su iconografía, a partir de unas fisonomías macilentas, como, de hecho, también se observa en la imagen de san Andrés, de manera que lo que en la estética barroca nace como un modo ${ }^{42} \mathrm{de}$ expresión condicionado, como pedía Gabrielle Paleotti, a "imágenes de santos que hicieron prolongadas abstinencias y se laceraron con ayunos y lágrimas" ${ }^{43}$-es decir, al asceta- adquiere en Gambino un nuevo valor semántico: el de transmitir y, sobre todo, hacer visible el contacto del Santo con la divinidad, aprovechando la factura lumínica que la propia concreción del rostro mediante sólo hueso y piel del modo asceta lleva implícita.

Asimismo, a un nuevo gusto de época responde el tratamiento que reciben los paños de estos dos apóstoles. En este sentido, Gambino construye las respectivas túnicas a partir de la estructura que, precisamente, introduce por vez primera en la plástica compostelana la primera mano de San Martín Pinario en obras como las de san José y san Francisco Forero (Fig. 12) consistente en "dos estrechos pliegues cónicos en los extremos [...] un gran corte inguinal sobre la pierna adelantada, para acusar la subyacente, y una disposición bastante vertical de los pliegues sobre el otro lado" ${ }^{44}$, y del vocabulario con que él mismo -Gambino- talla las piezas de san José y san Joaquín del retablo del coro bajo del convento compostelano del Carmen

\footnotetext{
42 Concepto que desarrolla Nicolas Poussin en 1647 en la carta que escribe a Paul Frèart de Chantelou. Se trata de un estilo aplicado: consiste en seleccionar los recursos estilísticos en función de un contenido en base a que sus efectos son los más adecuados al tema a desarrollar. J. BIALOSTOCKI, op.cit., pp. 13-36; S. MORALEJO, Formas elocuentes. Reflexiones sobre la teoría de la representación, Madrid, 2004, p. 125.

${ }^{43}$ Op.cit., fol. 280 r. ${ }^{\circ}$

${ }^{44}$ Ma C. FOlGAR DE LA CALle; J. M. LÓPEZ VÁZQUEZ, op.cit., p. 267.
} 
$(1757-1758)^{45}$, el cual, salvo sutiles matices, es el que define el conjunto de su producción durante este segundo período. Vocabulario que es fruto de seguir investigando en el camino que inicia tras el conjunto escultórico de la capilla del Pazo de Oca y que se traduce en unas telas que, respecto a las de la etapa precedente, ganan en artificio y pierden gravedad y volumen.

A través del artificio Gambino busca dotar de mayor belleza y arte a las figuras, por consiguiente, de acuerdo al reiterado nuevo gusto de época. El capricho ${ }^{46}$ del escultor, que lo lleva, conforme al credo artístico del momento, a utilizar el ingenio para introducir un sentimiento de vida en la obra, copiando la naturaleza, pero intentando mejorar sus imperfecciones, se pone en evidencia en el momento en que cotejamos los paños con que él diseña las imágenes de los dos apóstoles o de santa Catalina con aquellos otros que, tan sólo veinte años antes, emplean los herederos de Miguel de Romay en las esculturas de los retablos colaterales de Pinario. Decimos que se manifiesta la invención de Gambino en tanto en cuanto él, precisamente y como prueba el referido conjunto de Oca, se forma en y se vale de ese mismo vocabulario al inicio de su actividad. Se trata de un paño naturalista, grávido, volumétrico y de poca gracia, al tiempo que seña de identidad del lenguaje barroco compostelano de los años cuarenta y exponente del cambio que en el propio taller de Romay se produce en el tratamiento de las telas desde el punto y hora que, frente a las del primer tercio del siglo XVIII, se elimina cualquier referencia al estilo de Mateo de Prado, sobre todo en lo que al número de quebraduras y profundidad de

\footnotetext{
${ }^{45}$ R. OTERO TÚÑEZ, «El Carmen de Arriba (Carmelo de Santiago). Arquitectura y escultura», IV semana Mariana en Compostela, Santiago de Compostela, 1999, pp. 136-138.

${ }^{46}$ Ya Vicente Carducho entendía por capricho "el pensamiento nuevo del pintor" (op.cit., fol., 40v).
}

las mismas se refiere. $\mathrm{Y}$ es que el estilo de Prado, biológicamente inserto en el de Gregorio Fernández, se define por unos paños metálicos, como si estuviesen trabajados a percusión, y quebrados mediante profundos cortes $^{47}$, de lo que constituye un claro exponente el propio coro de San Martín Pinario (Fig. 11), empresa donde, precisamente, el escultor los introduce por vez primera en Galicia y con ellos su estilo de pleno lenguaje barroco en tanto en cuanto supone abogar por el juego de claroscuro que, como seña de identidad, lo define ${ }^{48}$.

Gambino, como decimos, transforma el paño naturalista y sin gracia de los colaterales a partir del expediente de restar dureza a los pliegues, reduciéndolos de tamaño, multiplicándolos en número e incrementando la esfericidad de sus concavidades y convexidades, así como su aristamiento, todo lo cual anima las figuras y las dota incuestionablemente de estilo y arte. Eso sí, a pesar del artificio, el imaginero no pierde de vista el sentido orgánico bajo el cual, desde el primer momento y frente a la plástica compostelana inmediatamente anterior, concibe sus esculturas. En este sentido, las imágenes de Miguel de Romay, como las de sus herederos de Pinario, se caracterizan por jugar con el dinamismo, la diversidad y la apertura de líneas cual corresponde al lenguaje barroco en que se mueven; sin embargo, en su caso, sólo se trata de un conjunto de recetas aplicadas sin tener en cuenta la verdadera esencia que se esconde detrás de su utilización: el orden, de manera que nos dejan confusos, obligándonos al raciocinio y a utilizar tiempo para poder entenderlas. Gambino, por el contrario, busca componer, es decir, que la pieza resulte un todo y cada una de

\footnotetext{
47 J. J. MARTín GONZÁLEZ, El escultor Gregorio Fernández, Madrid, 1980, p. 74.

${ }^{48}$ E. Orozco DÍAZ, Temas del Barroco de poesía y pintura, Granada, 1989, pp. XI-XII y 42.
} 
sus partes refuerce el conjunto, de forma que permita su completa percepción a un solo golpe de vista sin necesidad ni de raciocinio ni de temporalidad en su apreciación.

Consecuentemente, los pliegues que conforman las túnicas de los dos apóstoles están sabiamente pensados para acompañar y realzar, a través de su acompasado ritmo sinuoso y grácil caída, la elegante cadencia serpentina que dibuja el cuerpo de ambas figuras y a partir de la cual el escultor exhibe todo su talento dando vida al concepto de línea de la belleza con que Willam Hogarth precisamente la definía en su Análisis de la belleza (1753). Este esquema compositivo, aparte de contribuir al carácter refinado y delicado de las imágenes de acuerdo también a un nuevo gusto de época, no está menos pensado que el tratamiento de las telas, sino que su acento ascensional contribuye a visualizar ese estado de salirse de sí que presentan los dos apóstoles fruto de su anheloso abandono para fundirse con la divinidad.

Por lo tanto, no sólo el rostro, sino todo el cuerpo, se pone al servicio de hacer tangible la intangible alma y, de esta forma, también los paños que, además de subrayar la concepción sinuosa de la figura, están tan sabiamente pensados, como decimos, que a partir del corte inguinal y de la cuidada caída del pliegue central guían la mirada del espectador a la pierna exonerada, precisamente a aquella de la que parece arrancar el impulso de la imagen para metafóricamente elevarse, fruto en el san Andrés de presentar su talón convenientemente alzado y en el san Juan de posarlo sobre un pedestal, conforme al más puro lenguaje italiano; $\mathrm{y}$, además, están tan sabiamente pensados, que los dos pliegues laterales contiguos a la pierna exonerada refuerzan el carácter ascensional de la misma mediante su también ritmo ascendente hasta confluir en ella, a lo que asimismo contribuye, en la imagen de san Andrés, la colocación de la cruz en paralelo al propio pliegue lateral que, consecuentemente, redunda en su ritmo hacia lo alto: José Gambino, por consiguiente, lleva hasta sus últimas consecuencias la concepción de las imágenes como un todo orgánico. Lo mismo sucede en la pieza de santa Catalina.

Esta, atendiendo a su estatus regio, se representa ricamente alhajada en su vestuario, el cual sirve al escultor para expresar toda su maestría en la representación de las texturas de tres materiales distintos y, lo que quizá sea más importante para la estética de su tiempo, hacer de los ropajes un medio para alcanzar la perfección escultórica. En este sentido, los paños constituyen un completo catálogo de variaciones y combinaciones de formas y texturas, pero siempre respetando ese sentido orgánico de definir la escultura como un conjunto unitario, de manera que las telas se someten a la composición, engendrando o subrayando sus ritmos: obsérvese, pues, cómo los pliegues ascendentes de la túnica son recogidos y repetidos con otro tono y volumen por los de la sobretúnica, mientras que, por su parte, los del manto constituyen un tema compositivo distinto que refuerza el de los anteriores, potenciando el ímpetu ascensional de la figura y concentrando su clímax en la cabeza, fundamentalmente en la mirada extática de la Santa. Todo, por lo tanto y como en el caso de los apóstoles, al servicio de expresar, al tiempo que remarcar, su diálogo con la divinidad.

Incluso, las telas adquieren un valor semántico encontrándose al servicio de hacer visible la invisible presencia de la divinidad que sugieren, como hemos referido, los gestos fisonómicos y corporales de las distintas piezas de Pinario. Así, las túnicas y los mantos se mueven grácilmente como sacudidos por el soplo de un viento 
ligero, cual si se quisiese evocar el Numine afflatur ${ }^{49}$, mientras que se deshacen completamente en luz, como si a su vez estuviesen siendo bañados por el mismísimo resplandor celestial. A la hora de conferir a los paños este tratamiento lumínico, que con independencia de su fin expresivo responde también a un claro sentimiento de época, de ahí que constituya un rasgo característico del estilo del escultor durante esta segunda etapa, Gambino les suprime por completo el volumen que, merced a su formación en el lenguaje barroco compostelano -recordemos, en el oficio de las tallas de los colaterales de Pinario-, les concede en sus obras tempranas, al tiempo que los dota de un mayor aristamiento, lo que le permite traducir el diálogo entre la luz y la sombra de aquellas en un soliloquio a cargo de la primera. Estos dos recursos escultóricos se acompañan y refuerzan a partir de una rica policromía en oros que en su contacto con la luz, procedente en el caso de los apóstoles del alto ventanal de la cabecera de la Iglesia, hace comenzar una alegre sinfonía de brillos en los que vibra el alma extática de las figuras. En definitiva, todo un festín para los ojos del diletante, pero también para los del fiel, que, ante tanta belleza -respuesta, no se olvide, a una nueva época- sentiría la presencia de la divinidad.

Resta por señalar que facilita la contemplación de las imágenes, sin distracciones que disturben la atención de la trama que se representa, el hecho de que las mismas, conforme al camino que inicia Gambino en Oca, se conciben como elementos autónomos e independientes del entorno, que no se disuelven en él, sino que se cierran perfectamente en el mismo. A este fin, que encuentra su clímax en el clasicismo, responde la impecable valoración de la línea de contorno desde los distintos puntos

${ }^{49}$ W. WEISBACH, op.cit., p. 154. de vista espaciales; mantos y túnicas, estas últimas con sus pliegues laterales resueltos a partir de un ángulo obtuso conforme es seña de identidad del estilo del escultor, se purgan de cualquier quebradura que pudiese llevar a las figuras a integrarse y fundirse con el medio que las rodea. A ello cabe sumar en la pieza del Evangelista la sabia colocación del cabo volante de su manto, perfectamente cortado en chaflán, entre el águila y el libro, de manera que, a modo de muro, impide que la mirada del espectador se proyecte más allá de la imagen; por el contrario, la devuelve a esta para, además, reconducirla al ritmo ascensional de la figura que culmina en la magnífica cabeza toda ella expresión de su furor poeticus.

San Martín Pinario se convierte, por consiguiente, en la escuela compostelana de escultura durante los siglos XVII y XVIII: actúa como centro de atracción de artistas de primer nivel que, por un lado, serán copiados hasta la saciedad, marcando, así, el devenir del lenguaje compostelano a lo largo de las referidas centurias, y, por otro, serán adoptados como modelos para la invención por parte de otros creadores. $\mathrm{Y}$ una escuela de escultura siempre a la vanguardia: demanda, y cuando es el caso introduce en Compostela, aquellos lenguajes que, como diría Lafuente Ferrari ${ }^{50}$, satisfacen, conforme el valor expresivo del estilo, las angustias y necesidades de cada época.

${ }^{50}$ E. LAFUENTE FERRARI, La fundamentación y los problemas de la Historia del Arte, Madrid, 1951, pp. 122123. 


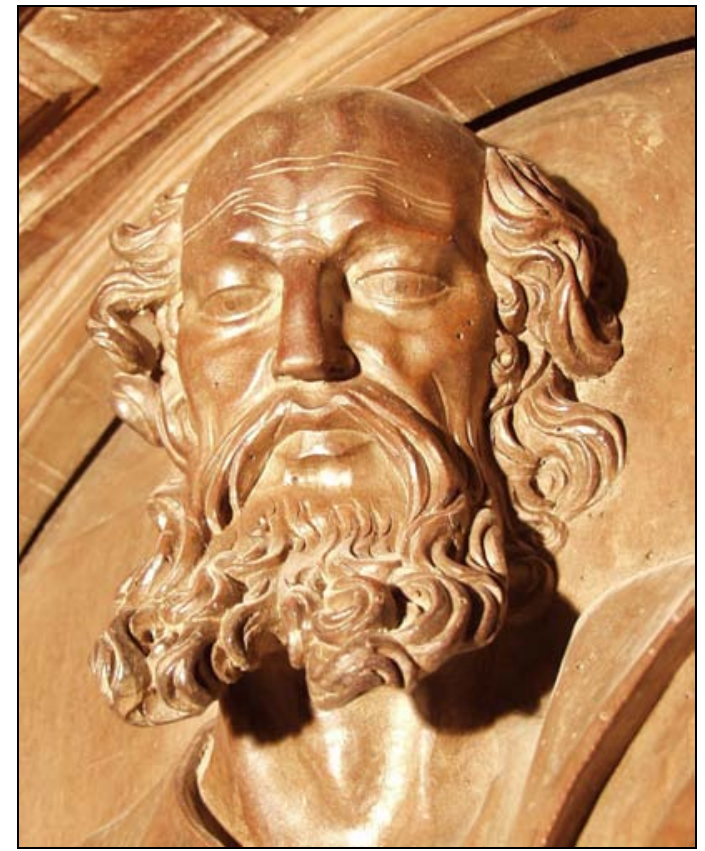

- Fig. 1. Detalle del tablero de san Pedro. Mateo de Prado. Coro de San Martín Pinario. 16391647.

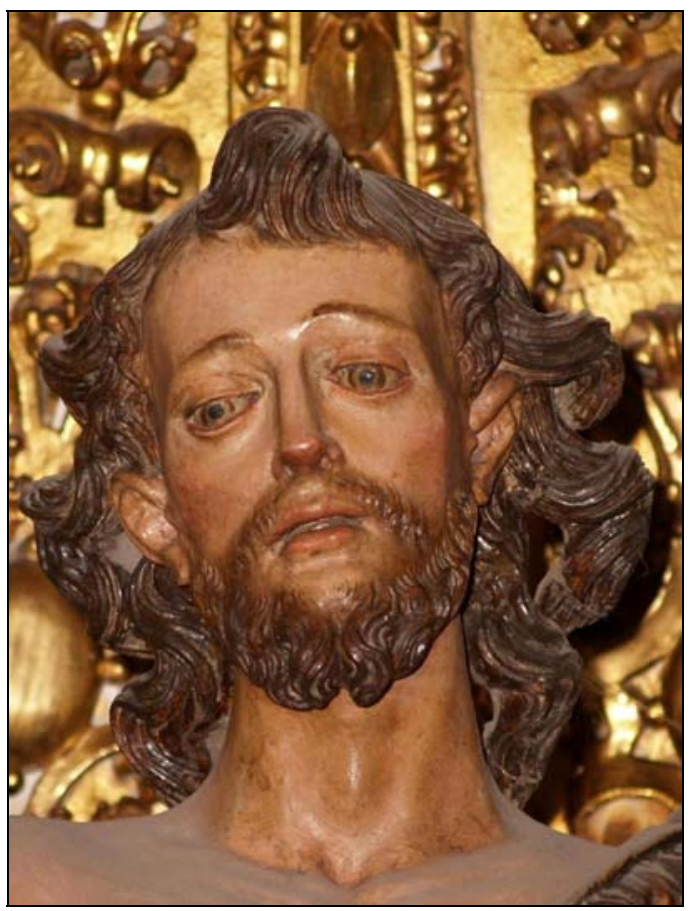

- Fig. 3. Detalle de san Juan Bautista. Segunda mano de San Martín Pinario: Andrés Ignacio Mariño. Retablo del Evangelio. 1742-1743.

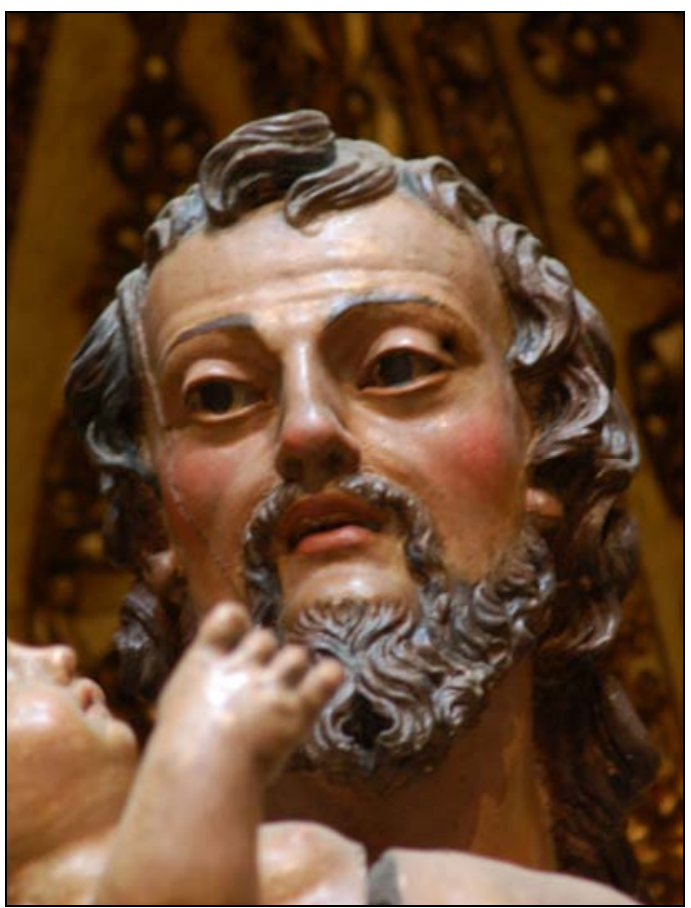

- Fig. 2. Detalle de san José. Primera mano de San Martín Pinario. Retablo del Evangelio. 1742-1743.

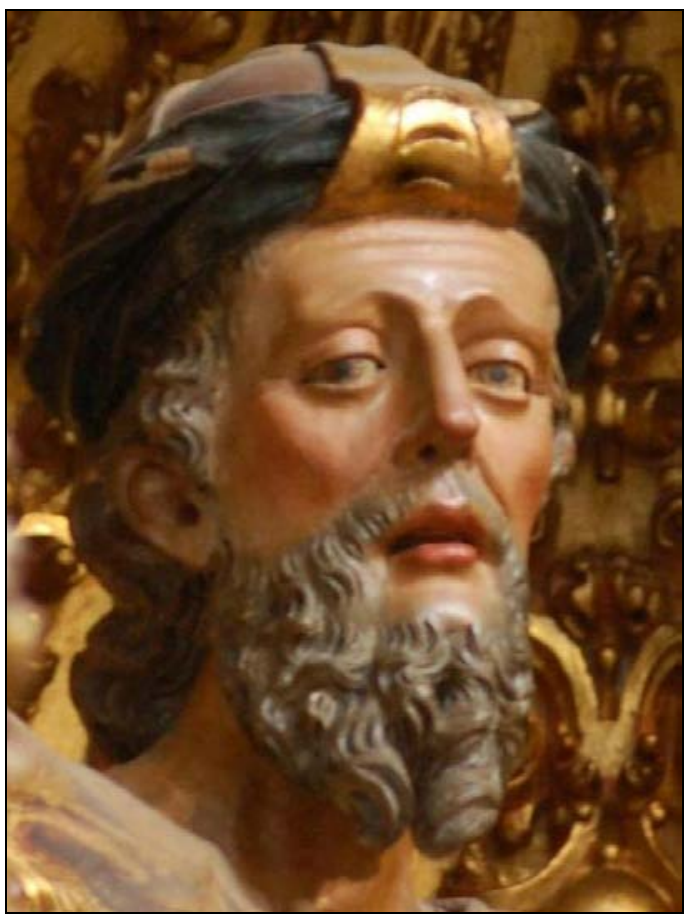

- Fig. 4. Detalle de san Joaquín. Segunda mano de San Martín Pinario: Andrés Ignacio Mariño. Retablo del Evangelio. 1742-1743. 


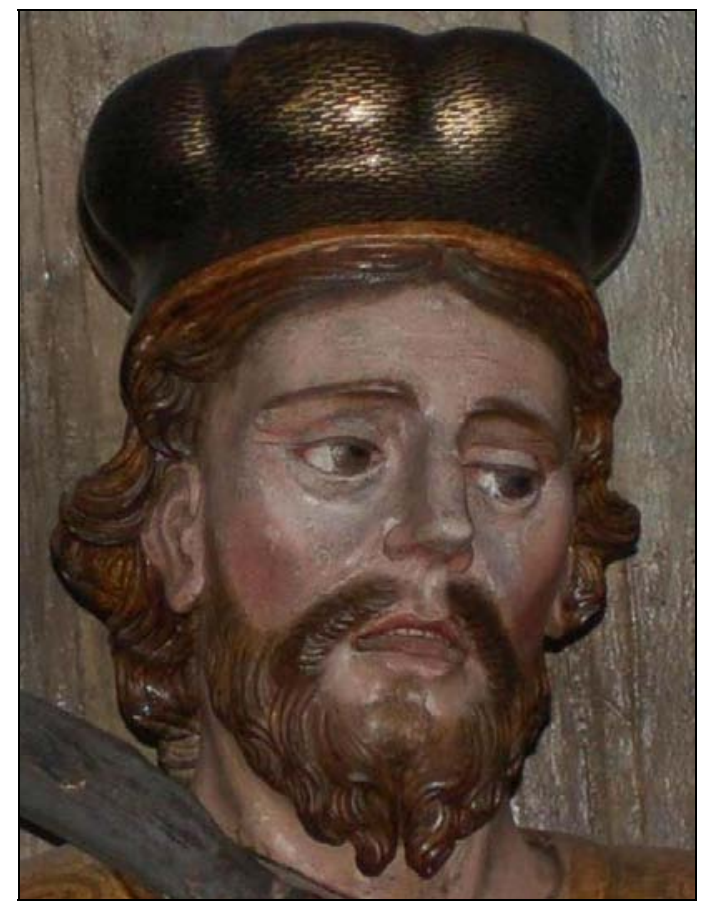

- Fig. 5. Detalle de san Cosme. Andrés Ignacio Mariño. Retablo Mayor. Capilla de San Roque (Santiago de Compostela). 1754

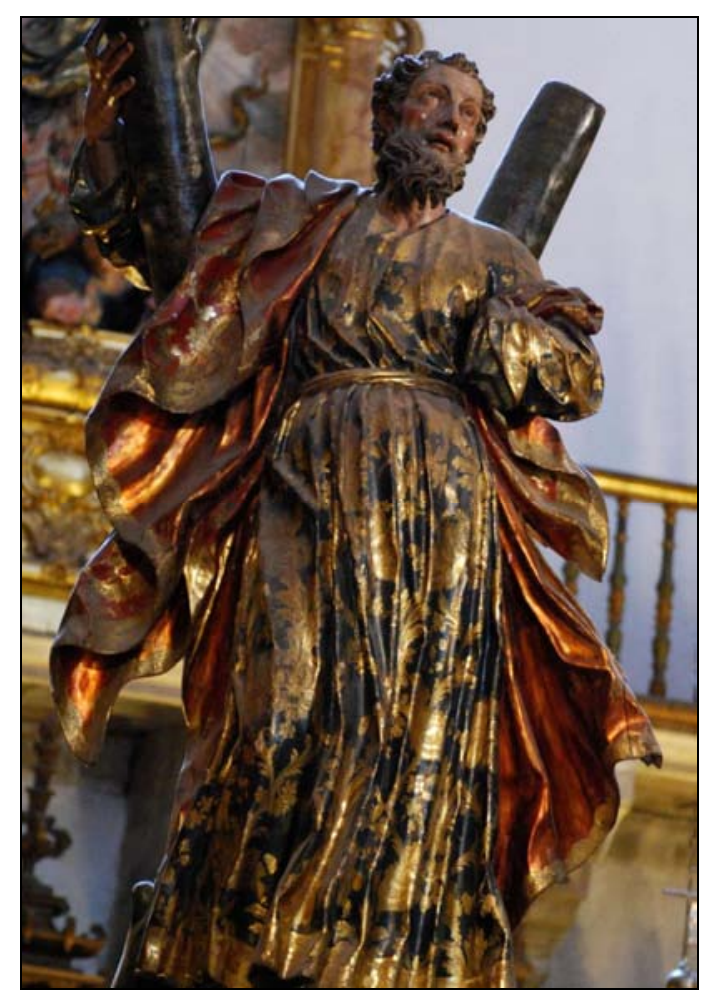

- Fig. 7. San Andrés. José Gambino. Retablo Mayor. San Martín Pinario. 1764..

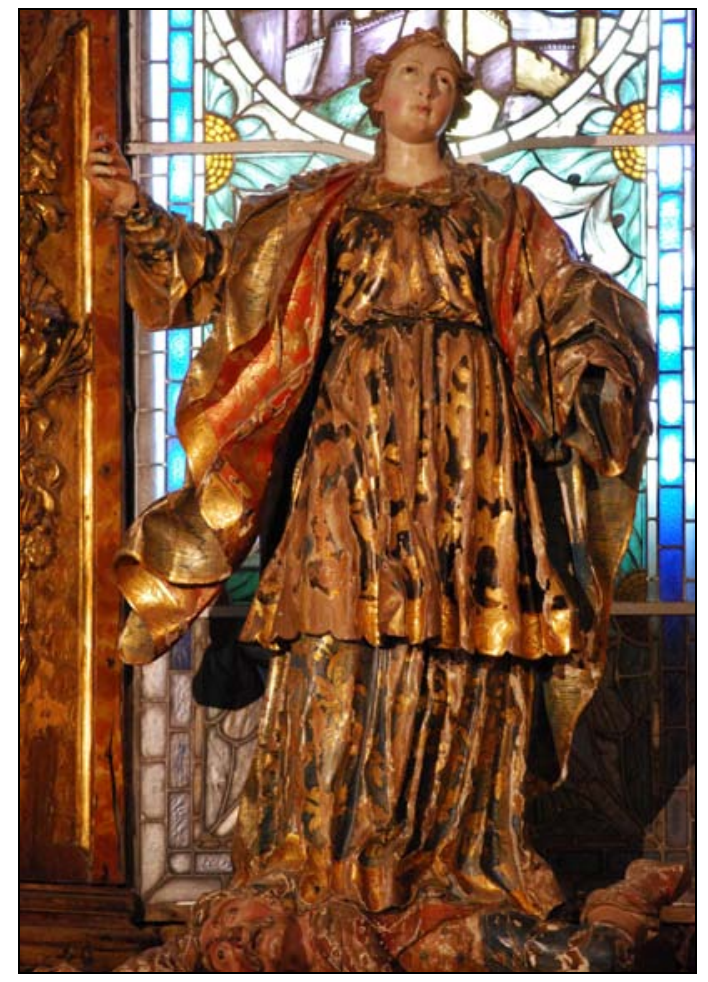

- Fig. 6. Santa Catalina de Alejandría. José Gambino. San Martín Pinario. 1763. 


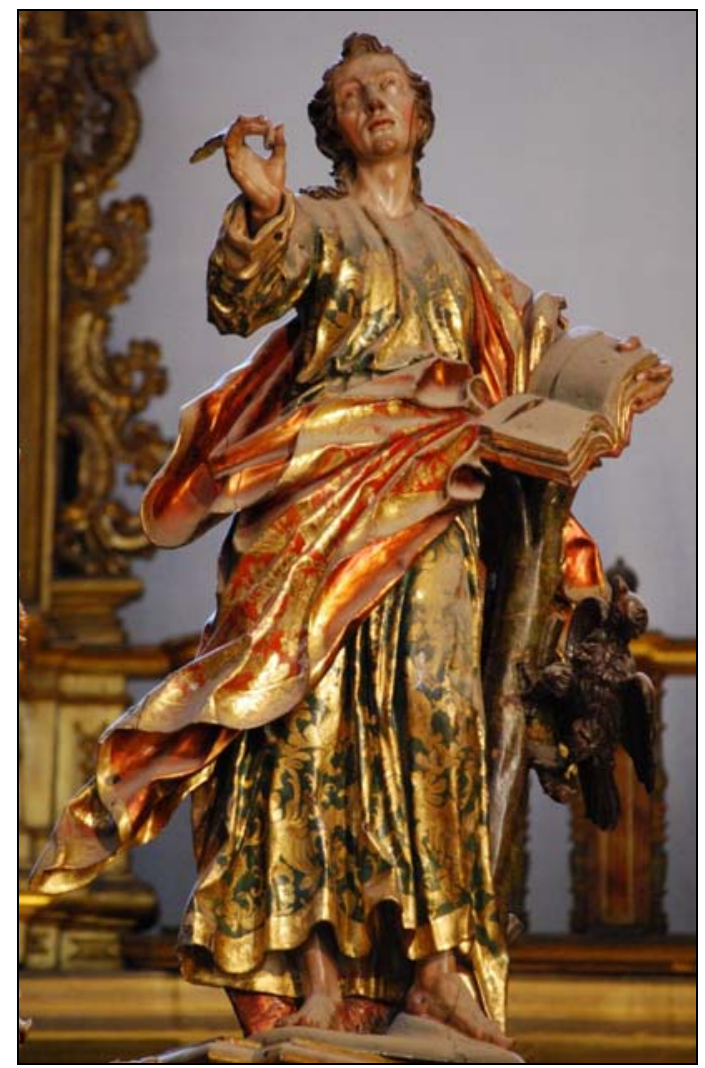

- Fig. 8. San Juan Evangelista. José Gambino. Retablo Mayor. San Martín Pinario. 1764.

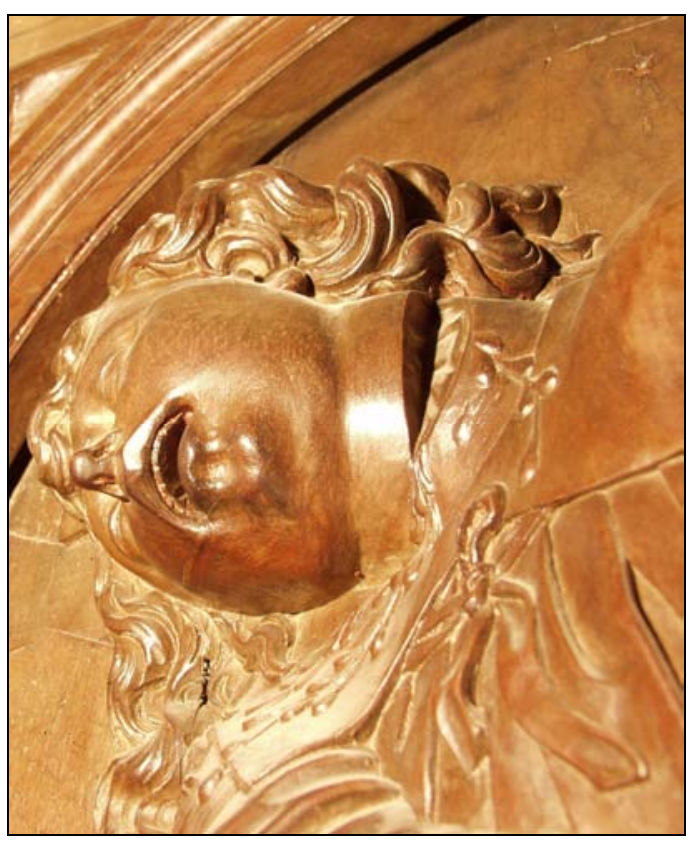

- Fig. 10. Detalle del tablero de san Pelayo. Mateo de Prado. Coro de San Martín Pinario. 1639-1647.

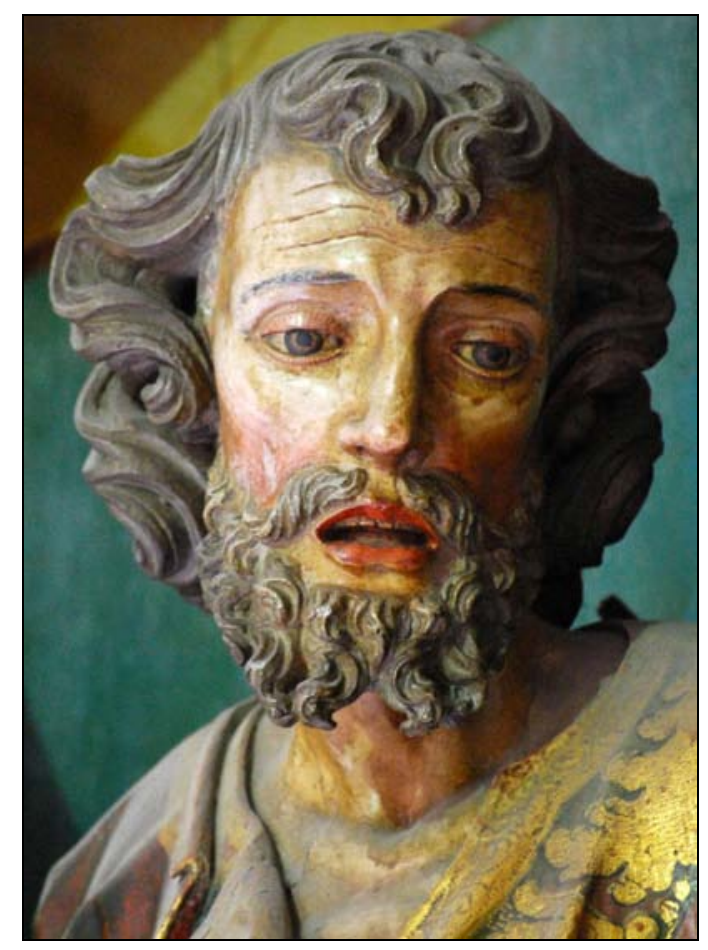

- Fig. 9. Detalle de san Andrés. Mateo de Prado. Sta. M. ${ }^{\text {a }}$ la Real de Conxo (Santiago de Compostela). 


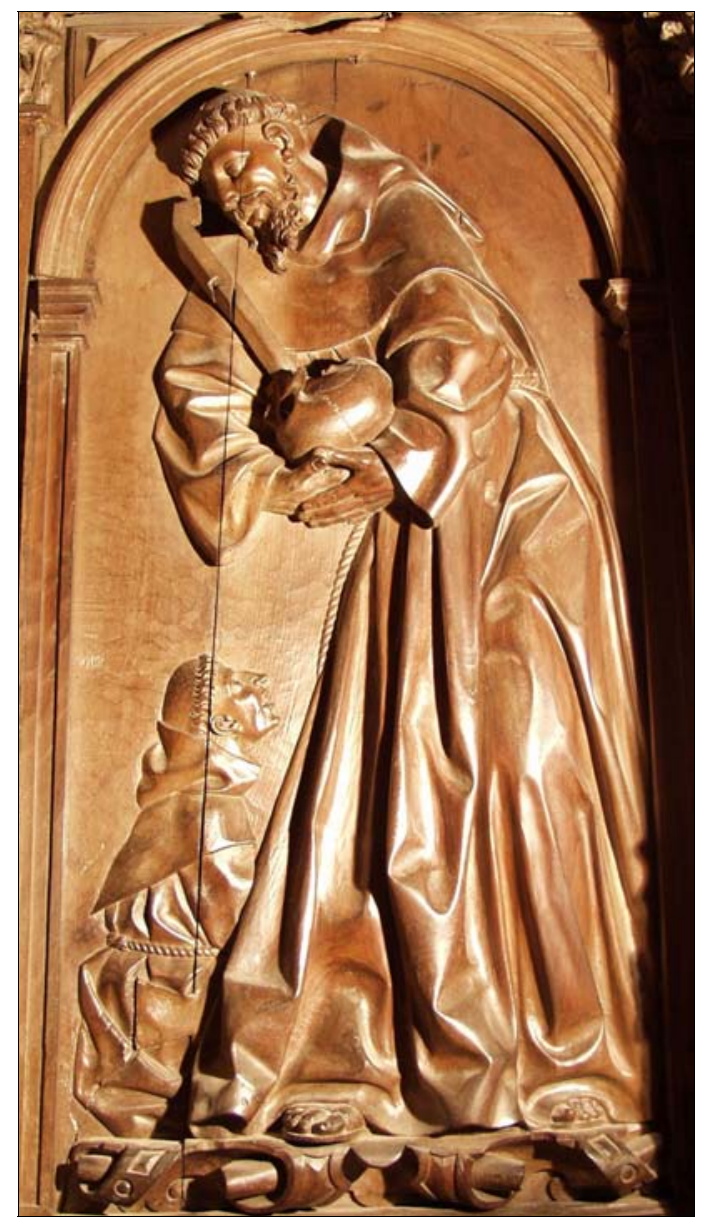

- Fig. 11. San Francisco de Asís. Mateo de Prado. Coro de San Martín Pinario. 1639-1647.

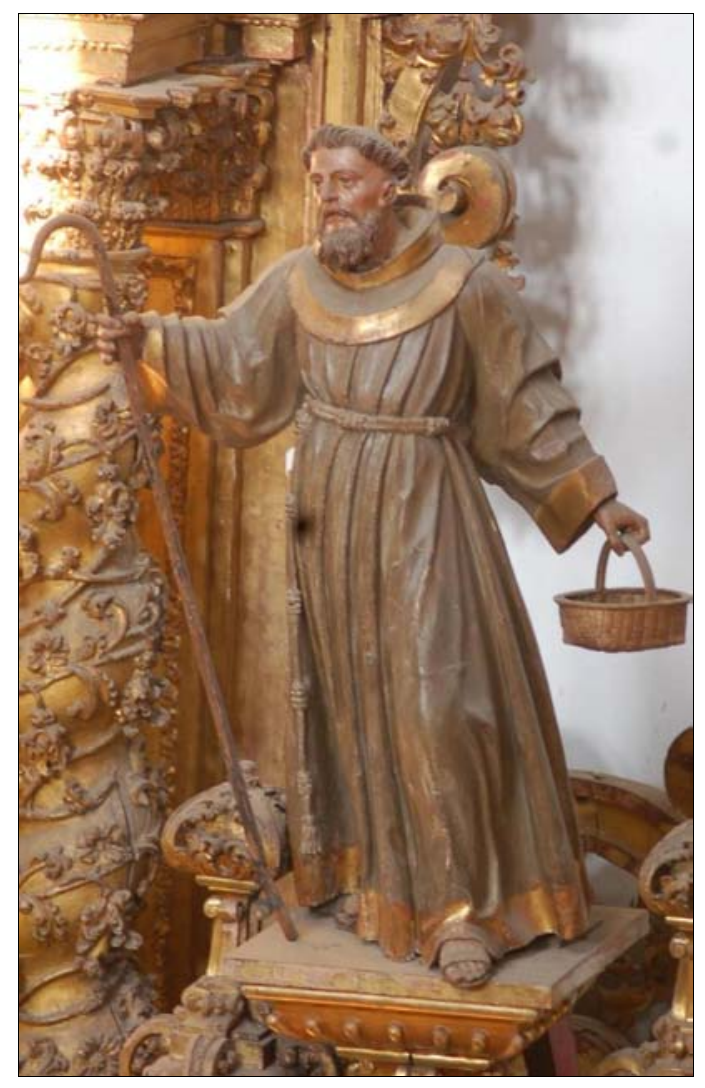

- Fig. 12. San Francisco de Asís. Primera mano de San Martín Pinario. Retablo de la Epístola. 1742-1743. 